\title{
Fibrinogen and rhegmatogenous retinal detachment: a pilot prospective study
}

This article was published in the following Dove Press journal:

Clinical Ophthalmology

13 February 2010

Number of times this article has been viewed

\section{IP Theocharis}

Ophthalmology Department, laso General Hospital, Athens, Greece
Correspondence: IPTheocharis Retina Consultant, Ophthalmology Dept, laso General Hospital, Skoufa 75,

Athens 10680, Greece

$\mathrm{Tel}+302 \mathrm{I} 036 \mathrm{I} 8074$

Fax +30 21 03647674

Email ioannistheocharis@hotmail.com
Purpose: To examine the correlation, if any, between fibrinogen plasma levels (FPL) and the clinical features of rhegmatogenous retinal detachment (RRD).

Methods: FPL were measured preoperatively in 33 patients with primary RRD. Patient characteristics and detachment features such as the numbers of breaks and the extent of the detachment were recorded;

Results: No statistically significant correlation was found between FPL and the number of breaks. A statistically significant correlation was found between FPL and the extent of the RRD, even if the influence of the number of breaks was excluded.

Conclusions: FPL correlate with retinal detachment extent, which implicates an acute inflammatory response to detachment traumatic phenomenon or a role of the fibrinogen molecule in retinal adhesiveness.

Keywords: fibrinogen, retinal detachment, pathogenesis

\section{Introduction}

Fibrinogen, the circulating precursor of fibrin, is a high-molecular-weight glycoprotein. Research findings incriminate elevated fibrinogen levels as a strong independent risk factor for the occurrence of initial and recurrent cardiovascular events. ${ }^{1}$ Other evidence cited in the discussion indicates a role of fibrinogen in processes such as proliferation, wound healing, and inflammation. In addition, elevated fibrinogen plasma levels (FPL) are considered a risk factor for idiopathic macular hole and are a predisposing factor for vision loss by diabetic retinopathy as well as for age-related macular degeneration. ${ }^{2-4}$ Obviously, there is a reflection of the circulating fibrinogen in the eye.

Retinal susceptibility to traction and healing properties are determinative factors in the pathogenesis of rhegmatogenous retinal detachment (RRD). In a previous study, Theocharis and colleagues found that FPL were elevated in retinal detachment patients and even more elevated in proliferative vitreoretinopathy (PVR) patients compared with a control group. ${ }^{5}$ This article further examines the role, if any, of FPL in the development of primary RRD, a traumatic sight-threatening phenomenon for the eye.

\section{Materials and methods}

The present prospective study included patients with primary RRD presented to our clinic during the first 48 hours after the onset of retinal detachment symptoms (defect on visual field). Known diabetics patients with cardiovascular disease, liver disease, nephropathy, or systemic inflammatory disease were excluded, because of 
the strong positive relationship between these conditions and fibrinogen levels. Other exclusion criteria were former lazer retinopexy or vitreoretinal surgical treatment, which could alter the progression of the retinal detachment, retinal liaisons due to age-related macular degeneration or macula hole in at least one eye, which are associated with elevated FPLs, and at least one large break with size more than 3 disc diameters. Large breaks accelerate the progression of a detachment due to increased tractional forces and massive fluid flow through the break. Signs of PVR more than grade A according to the Retina Society Terminology Committee were also exclusion criterion. All measurements were taken preoperatively and during the current semester in order to standardize patients for preoperative stress and seasonal fibrinogen level fluctuation. Patient ages ranged from 40 to 75 years. The von Clauss method was used to determine fibrinogen in the blood samples. The international standard for this method is $2.4 \mathrm{~g} / \mathrm{L}$. Our laboratory suggests a normal limit between 2 and $4 \mathrm{~g} / \mathrm{L}$. The mean value of FPL determined by the multicenter Framingham Heart Study was $2.9 \mathrm{~g} / \mathrm{L}$, with a standard deviation of $0.6 \mathrm{~g} / \mathrm{L}$. A 95\% confidence level in the study required a sample size of 33 patients based on the above standard deviation of $0.6 \mathrm{~g} / \mathrm{L}$. The primary endpoint was the presentation of the $33 \mathrm{rd}$ patient. Pearson correlation test, partial correlation test, and regression analysis was used to examine the correlation between FPL, the number of breaks, patient age, and number of detached quadrants (NQD).

\section{Results}

A starting date was scheduled. Thirty-three patients with primary RRD were enrolled in the study. Seven patients were pseudophakic and one had history of YAG-laser capsulotomy after posterior capsule opacification. No patients had ophthalmic surgery during the last two months before their presentation at the clinic. One patient had complicated cataract surgery with posterior capsule rupture four months before the detachment. Twelve percent of the patients had lattice degeneration at the retinal periphery, $14 \%$ had the macula off, and no one presented with signs of long standing retinal detachment. The maximal break size was 3 disc diameters in two cases. Twenty out of 33 patients had segmental (less than two quadrants) detachment and five had totally detached retina (Figure 1). In total, 74 breaks were recorded: 10 out of 74 were inferior (between 4 and 8 o'clock) and a sole inferior break as the cause of the detachment was found in one case;

Fibrinogen plasma levels (FPL) did not show any statistical correlation with patient age and the number of breaks as the Pearson coefficient $(r)$ in both comparisons was close to zero. Statistically significant $(P<0.02)$ correlation was found between FPL and the NDQ with a coefficient $r=0.41$ and coefficient of determination $r^{2}=0.17$. As expected, the number of breaks correlated with NDQ with $r=0.39$ and $r^{2}=0.15$. Coefficient of determination $\left(r^{2}\right)$ reflects the strength of the association between the two variables and it could be used to compare different pairs of comparisons;

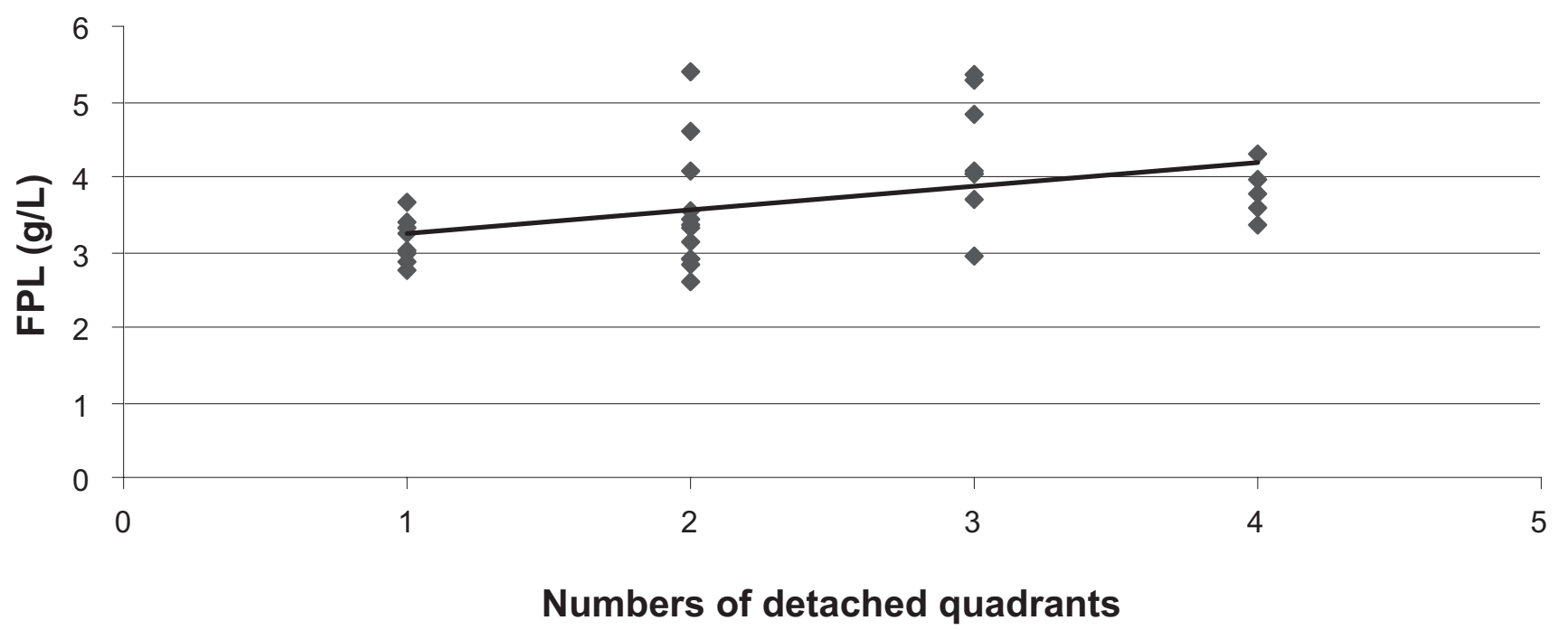

Figure I Fibrinogen and extension of the detachment (scatter plot).

Notes: Each point represents one retinal detachment case.

Abbreviation: FPL, fibrinogen plasma levels. 
Table I Descriptive characteristics of patients' groups per number of detached quadrants

\begin{tabular}{lllll}
\hline & $\mathbf{l}$ qd & $\mathbf{2}$ qd & $\mathbf{3} \mathbf{~ q d}$ & $\mathbf{4} \mathbf{q d}$ \\
\hline Median FPL & $3.13 \mathrm{~g} / \mathrm{L}$ & $3.33 \mathrm{~g} / \mathrm{L}$ & $4.07 \mathrm{~g} / \mathrm{L}$ & $3.76 \mathrm{~g} / \mathrm{L}$ \\
Mean FPL & $3.15 \mathrm{~g} / \mathrm{L}$ & $3.505 \mathrm{~g} / \mathrm{L}$ & $4.32 \mathrm{~g} / \mathrm{L}$ & $3.79 \mathrm{~g} / \mathrm{L}$ \\
SD FPL & $0.3 \mathrm{~g} / \mathrm{L}$ & $0.8 \mathrm{~g} / \mathrm{L}$ & $0.82 \mathrm{~g} / \mathrm{L}$ & $0.35 \mathrm{~g} / \mathrm{L}$ \\
\hline
\end{tabular}

Abbreviations: FPL, fibrinogen plasma levels; qd, quadrants of detached retina; STDV, standard deviation.

thus, FPLs correlate stronger than the number of breaks with the extent of the detachment. The NDQ, considered as the dependent variable, was influenced by two independent variables: the FPL and the number of breaks. In order to subtract the influence of the number of breaks upon the relationship between FPL and NDQ, a partial correlation test was performed resulting in the following: partial coefficient $r \mathrm{p}=0.426, r \mathrm{p}^{2}=0.182, P=0.015$. Evidently, the correlation between FPL and NDQ became stronger. Taking into account that almost all cases with total detachment have FPL underneath the trendline in Figure 1, patients were categorized according to the NDQ as shown in Table 1. It is obvious that both median and mean values decline in the group of four quadrants (qd) following an ascending course. A possible explanation is discussed in the next section. The correlation between FPL and NDQ, restricted to those patients $(n=28)$ with a maximum of three qd of retinal detachment became much more determined and tests resulted to $r=0.53, r^{2}=0.28$, $r \mathrm{p}=0.57, r \mathrm{p}^{2}=0.32, P<0.01$. Regression analysis could predict FPL in $72 \%$ of those cases with a standard error of $0.7 \mathrm{~g} / \mathrm{L}$, taking as separate independent variables the NDQ and the number of breaks.

\section{Discussion}

Gender as well as other environmental and biochemical factors such as cigarette smoking, obesity, elevated hematocrit and dyslipidemia are known from the literature to significantly affect fibrinogen levels. The sample of the patients of this study was not standardized for all these factors. On the other hand, such a study design would require several semesters to reach the primary point. Gravity may influence the extent of the detachment in a given time period; thus the location of the break is an important factor. Our clinical impression is that the onset of RRD symptoms from inferior detachments usually comes later compared to superior detachments and patients with inferior detachments seek for medical help later. These facts and the exclusion criteria of the study could explain why the vast majority of the breaks were superior and only in one patient the cause of the detachment was an isolated inferior break.
As the results of the present study indicate, FPL show a relatively strong, positive, and statistically significant $(P<0.02)$ association with the extent of a retinal detachment, excluding the effect of age and the number of breaks on this association. This raises the question of whether the correlation between fibrinogen and retinal detachment is based on a direct causation, a common cause, or on a confounding factor.

Choroidal ischemia leads to blood-retinal barrier (BRB) breakdown, local retinal detachment, proliferation of retinal pigment epithelium (RPE) cells and photoreceptor degeneration. ${ }^{6}$ As elevated FPL lead to a predisposition to microangiopathy, reflecting the inflammatory condition of the vascular walls as well as the altered blood viscosity and intravascular fluid hydrodynamics, they may induce chorioretinal hypoxia and BRB disturbance, influencing the adhesion of anatomically attached retina after a retinal break formation. ${ }^{1}$ Fibrinogen/fibrin/thrombin complex induces contraction and increases the permeability of endothelial cells. ${ }^{7}$ High levels of fibrinogen lead to unstable fibrin formation, resulting in abnormal healing and an increase of fibrin degradation products, which are mitogenic. ${ }^{8}$ These two mechanisms may increase retina susceptibility to vitreous traction, meaning that in a chronic or recurrent setting, elevated FPL may alter retinal-RPE adhesion properties. Hence the subretinal fluid might be propagated easier and more quickly, enlarging the area of the detachment. Our results support this hypothesis, that the onset of symptoms, described by the patients, refers approximately to the same detachment area. In detail, among patients with only one break, the group which had 3 or 4 qds of detached retina had statistically significant higher levels of fibrinogen than the group which had only one qd. Thus, for the same duration of the detachment, the first group demonstrated a higher tendency than the latter towards the progress of the detachment or consequently less adhesive strength between retina and RPE.

Another way to interpret the results of the study is to consider retinal break formation and retinal detachment as a traumatic phenomenon, which triggers an acute inflammatory response. In such a response, small blood vessels adjacent to the area of tissue damage initially become dilated with increased blood flow, and then flow along them slows down. Endothelial cells swell and partially retract so that they no longer form a completely intact internal lining. The vessels become leaky, permitting the passage of water, salts, and some proteins from the plasma into the damaged area (exudation). One of the main proteins to leak out is the soluble molecule, fibrinogen. Exudation of a fluid rich in fibrinogen, 
called fibrinous exudate, will clot to form a yellowish gel and pseudomembranes. Wherever two opposing surfaces have a fibrinous exudate between them, the organization of the fibrin leads to adhesion. The inflammatory phase has a rapid onset (a few hours) and swiftly increases in magnitude to its maximal reaction (2-3 days) before gradually resolving. Fibrinogen is known as a positive acute phase reactant. Histological examination of subretinal strands after RRD and immunostaining of early preretinal exudates and recently the increased level of fibrinolytic components in the vitreous, indicate fibrin/fibrinogen presence in eyes suffering with retinal detachment. ${ }^{9-11}$ Specific binding with collagen type IV is an additional significant observation. ${ }^{12}$ Of note, intraocular fibrinogen injection induces vitreous membrane formation in rabbits. ${ }^{13}$ Taken together, these findings could support the following hypothesis: The progress of retinal detachment causes elevation of the FPL. Unfortunately, in the present study there were no available data on fibrinogen plasma concentrations before the occurrence of the retinal detachment, but there are two interesting observations, that may support the aforementioned hypothesis. First, there is temporal consistency between the expected time of acute phase reactions and the observed FPL behavior, and second, FPL tend to decrease when retinal detachment is total (4 qds) and the process reaches its conclusion. The latter may reflect the beginning of a gradual cessation of the acute inflammatory response.

The present study was based on the hypothesis that elevated plasma levels of fibrinogen, a key molecule in blood circulation, inflammation, and healing process, may predispose to decreased retinal adhesiveness. Additionally FPL may increase as part of an acute phase response to retina trauma after a retinal break formation. The interpretation of the results indicates, but not clarifies, fibrinogen's role in retinal detachment.

\section{Disclosure}

The author has no proprietary or conflict interest in this work.

\section{References}

1. Kannen WB. Influence of fibrinogen on cardiovascular disease. Framingham Heart study. Drugs. 1997;54(Suppl 3):32-40.

2. Risk factors for idiopathic macular holes. The Eye Disease Case-Control Study Group. Am J Ophthalmol. 1994;118(6):754-761.

3. Sjolie AK, Stephenson J, Aldington S, et al. Retinopathy and vision loss in insulin-dependent diabetes in Europe. The EURODIAB IDDM Complications Study. Ophthalmology. 1997;104(2):252-260.

4. Smith W, Mitchell P, Leeder SR, Wang JJ. Plasma fibrinogen levels, other cardiovascular risk factors, and age related maculopathy: the Blue Mountains Eye Study. Arch Ophthalmol. 1998;116(5):583-587.

5. Theoharis IP, Mangouritsas G, Feretis E. Fibrinogen and detached retina with or without proliferation. Acta Ophthalmol Scand. 2000;78(6): 660-662.

6. Algvere P. Retinal detachment and pathology following experimental embolization of choroidal and retinal circulation. Graefes Arch Clin Exp Ophthalmol. 1976;118960:754-761

7. Smith EB. Fibrinogen, fibrin and the arterial wall. Eur Heart J. 1995;16(Suppl A):11-14.

8. Mannucci PM. Recent progress in pathophysiology of fibrinogen. Eur Heart J. 1995; 16(Suppl A):25-30.

9. Trese MT, Chandler DB, Machemer R. Subretinal strands: ultrstructural features. Graefes Arch Clin Exp Ophthalmol. 1985;223(1):35-40.

10. Peczon BD, Wolfe JK, Gipson IK, Hirose T, Buzney SM, Schepens CL. Characterisation of membranes removed during open sky vitrectomy. Invest Ophthalmol Vis Sci. 1983;24(10):1382-1389.

11. Ulrich JN, Spannagl M, Kampik A, Gandorfer A. Components of the fibrinolytic system in the vitreous body in patients with vitreoretinal disorders. Clin Experiment Ophthalmol. 2008;36(5):431-436.

12. Jones M, Gabriel DA. Influence of the subendothelial basement membrane component on fibrin assembly. Evidence for a fibrin binding site on type IV collagen. J Biol Chem. 1988;263(15):7043-7048.

13. Mansour AM, Chess J, Henkind P. Fibrinogen induced vitreous membranes. Ophthalmic Res. 1987;19(3):164-169.
Clinical Ophthalmology

\section{Publish your work in this journal}

Clinical Ophthalmology is an international, peer-reviewed journal covering all subspecialties within ophthalmology. Key topics include: Optometry; Visual science; Pharmacology and drug therapy in eye diseases; Basic Sciences; Primary and Secondary eye care; Patient Safety and Quality of Care Improvements. This journal is indexed on Submit your manuscript here: http://www.dovepress.com/clinical-ophthalmology-journal

\section{Dovepress}

PubMed Central and CAS, and is the official journal of The Society of Clinical Ophthalmology (SCO). The manuscript management system is completely online and includes a very quick and fair peer-review system, which is all easy to use. Visit http://www.dovepress.com/ testimonials.php to read real quotes from published authors. 